\title{
Teachers' Professional Development from the View of Ecological Civilization
}

\author{
Yimei Ren, Qian Wu, Likun Gao, Yifan Cao \\ Tianjin University of Technology and Education \\ Teaching ability and professional capability Research Center \\ renyimei2005@163.com
}

\begin{abstract}
The study observed teachers' educational activities from the view of ecological civilization. We found that teachers' professional development is a continuous process. The school that teachers worked in is an important foundation. Society and school offer professional acknowledge and educational resources respectively. To sum up, excellent social situation and school compose the outside environment for teachers' professional development, while lifelong learning composes the inside characteristic.

Index Terms -professional development of teachers, lifelong learning, universities, society, and ecological environment
\end{abstract}

\section{生态文明视域下的教师专业成长}

\author{
任毅梅 吴倩 高丽坤 曹伊凡 \\ 天津职业技术师范大学 \\ 天津市普通高等学校人文社会科学重点研究基地师范能力与职业能力研究中心 \\ renyimei2005@163.com
}

\begin{abstract}
摘要 从生态文明的视角观察教师教育活动 过程, 发现教师专业化是一个持续发展的过 程, 教师从业的学校是教师专业成长的土壤 环境, 社会对教师专业化的认知以及大学为 教师的专业成长提供丰富的教育资源是教师 的专业成长的气候环境。良好的外部条件构 成教师专业成长的生态环境。终身学习是教 师专业成长的动力源泉。
\end{abstract}

关键词: 教师专业成长 终身教育 学校社 会 生态环境

\section{1. 引言}

国家中长期教育发展纲要中指出 “百年 大计, 教育为本。教育大计, 教师为本”。 民族崛起的希望在教育，教育振兴的希望在 教师。教师承担着为国家培养人才的历史重 任, 教师的教育教学水准直接影响到一个国 家、一个地区公民素质的提升和各级各类人 才培养的质量。

教 师 专 业 化 (teacher professionalization) 是指教师在整个从业过程 中, 通过终身专业训练, 依托专业组织, 习 得教育专门知识与规范, 形成教育教学能力, 取得教师资格, 实施专业自主, 表现专业道 德，逐步提高自身从教素质，成为一个良好
的教育专业工作者的专业成长的过程。也就 是从一个 “普通公民” 变成 “教育者” 的专 业发展过程。

教师专业化强调的是一个过程。在这个 过程中 “个人成为教学专业的成员并且在教 学中具有越来越成熟的作用这样的一个转变 过程”。这一变化过程并不因为教师本人曾 经接受了职前教师教育或毕业于师范大学, 到他们开始从事教师职业就终止了。这种个 人专业素养的提升、成长的过程在持续不断 地进行, 是贯穿于教师职业生涯的整个过程。

由此可见，教师的专业化过程是一个持 续的、动态的、发展的过程。教师的专业化 过程不是指某个教师、某几个教师, 而是指 整个教师群体。同时教师专业化过程也不是 孤立的, 需要与周围的环境发生密切的联系。

生态 (Eco-) 一词源于希腊语, 意思之 一是指环境。如今，“生态”一词涉及的范 畴也越来越广, 生态学已经渗透到各个领域, 人们常常用 “生态” 来定义许多美好的事物。 生态文明是人类为保护和建设美好生态环境 而取得的物质成果、精神成果和制度成果的 总和。

借助生态环境这一术语, 将教师专业成 长的环境因素, 比喻成生态环境, 十分形象。 
显然, 认识环境因素对教师专业成长的重要 性, 营造一个和谐的教师专业成长的可持续 发展的生态环境, 在教师专业化过程中是不 容忽视的关键。

\section{2. 教师劳动的复杂性}

众所周知，教师的责任是育人。教师是 人类科学知识和文明的传播者, 承载着人类 进步、发展的美好希望, 这也是教师职业区 别于其他职业的重要特征。教师被认为是 “太 阳底下最光辉的职业”。教师职业的专业性 体现在教师每一刻都要面对复杂万变的教育 情境, 面对成长中的不同学生个体, 做出科 学的决策并采取行动。同时, 教师职业的专 业性是教师群体的社会行为, 其专业性也体 现在教师群体专业水平的不断提升。

我国培养教师的主渠道是师范生的职前 教育。师范生经过大学本科四年或者是研究 生阶段的学习, 从大学校门走进所任教学校 的校门, 由学生转变为教师身份, 有些教师 能迅速地成长为胜任的甚至是优秀的教师。 而有些教师完成这样一个过程则需要很长的 时间。

当我们认为某些人在教学领域干得十分 出色, 成为行业专家时, 人们往往把广博的 专业知识, 高超的技术水平, 具备熟练的操 作等特质联系在一起。

这其中最不容忽视的是，专家型教师能 够在瞬息万变的、复杂的、困难的条件下， 灵活运用教育理论，对育人过程做出准确的 分析和判断。这是专家型教师和普通教师的 本质区别。他们应对复杂的教育教学活动游 刃有余，从容地解决发生的各种难题。

众所知道, 一堂生动活泼的课, 往往不 是靠固定程序能设计出来的。教师需要凭借 教育智慧, 建立所教授的学科知识理论与生 产、生活实践的联系，吸引学生的关注，带 领学生走进学习情境。其次, 教师备课的关 注点也不同，专家型教师往往有多个方案可 供学生选择, 他们更关注学生的个体差异, 恰当地鼓励学生, 调动学生的主观能动性, 在教学中往往灵活整合知识, 使教材的内容 与学生的实际水平相吻合, 引导学生运用所 学知识, 灵活、创造性地解决问题, 而不是 照本宣科，照流程行事。专家型教师驾驭课 堂的能力源于教育教学实践的积累, 源于对
教育教学的研究、体验、反思。他们将教育 经验升华为教育理论, 这不是一朝一夕的功 夫，也不是一蹴而就的事情。因此教师的专 业成长需要时间和实践, 需要反思的过程和 成长的氛围。

\section{3. 教师专业成长的土壤一一学校的生态环境}

就像万物的生长靠太阳一样，教师专业 成长离不开的环境因素的影响。学校是教师 专业成长的重要场所和平台。教师的专业发 展依托学校而展开，没有学校这片沃土，教 师专业成长的树木没有根基。教师从新手成 长为合格教师、甚至是专家型教师的重要途 径是学习——实践——再学习——再实践, 教师任教的学校, 为教师的专业成长提供了 实践的场所。

新手教师通过观摩其他教师的课堂行为 和课后行为, 揣摩教学中遇到的问题, 可以 随时获取专业成长所需要的各种信息, 学校 为教师观摩各种课程的教学，提供了丰富的 样板, 新教师在向有经验教师的学习中不断 成长，走向成熟。

教师的专业成长，离不开学校的教学研 究氛围。通过教学研究, 教师与同行之间及 时交流探讨教育教学中遇到的问题, 解决他 们自己解决不了的困难，并能很快将意识层 面的观念付诸实践，加以验证、体会。因为 教学环境、教学情境的相似性，使得这种研 究更具有借鉴和参考的价值。教师之间相互 学习, 带动的是整个团队的成长。另外, 教 学研究使得教师的备课不再是个人行为, 也 不再是简单地备内容、备教学环节、写教案 等, 教师之间十分便利地吸收他人的有效经 验，从封闭走向更开放。

学校是教师天然的、永久的教学实验基 地, 使教师的理论与实践合二而一; 学校是 教师创造性劳动的展示平台，课堂加速了教 师的专业成长。教师与学校在环境互动中实 现双赢, 学校因为教师群体的专业水准而享 有良好的社会声誉, 受到学生与家长的信任, 吸引到更优秀的教师，而教师之间因为有高 手的存在而加速专业水平的提升。

\section{4. 教师专业成长的气候一一社会的生态环境}

如果把学校比喻成教师专业成长的沃 土，那么社会便是教师专业成长的气候了。 教师专业化的另一个重要方面, 源自于社会 
对教师职业的普遍认知程度。教师需要像医 生、律师一样享有一定的职业声望。首先社 会公众应该普遍知晓教师是经过专业训练的 人, 教师的培养由职前教育、入职教育和职 后培训一整套培训体系构成, 并经过国家资 格认证。其次是教师的培养机构一大学对 教师职前培养过程中对教师专业知识的重 视, 即教师职前培养过程中专业知识与学科 知识的构成比重。目前我国的教师教育往往 重视学科知识, 轻视教师专业知识。从大学 四年的课程安排上就能体现出这样的问题。 学生在大学期间主要学习学科知识, 关于教 师专业知识, 仅有教育学、心理学、微格教 学、和 “三字一话”、教育实习等胗胗无几 的课程, 学生不重视, 教师没热情。虽然各 个学校, 特别是师范大学对教师教育课程进 行改革, 学生直到开始从事教师职业时方知 道教师劳动的复杂性和课堂的多变性, 部分 同学才找来教育学、心理学的书恶补专业知 识, 根本没有循序渐进, 形成真正的教育教 学能力。虽然各个学校, 特别是师范大学对 教师教育课程进行了改革, 但没有从根本上 扭转这种轻视教师专业培养的局面。追求教 育的急功近利行为, 没有真正认识到教师的 专业化的意义, 没有像培养医生那样培养教 师, 是造成这种局面的重要原因。解决教师 职前培养中学科教育与教师专业教育在课时 分配方面的冲突, 师范大学的教育类课程应 该更为开放和丰富, 为准教师利用教育资源, 学到更多的、他们感兴趣的诸多教育类课程 提供可供选择的机会。

\section{5. 教师专业成长的动力一个人职业认知与 终身学习}

教师职业的挑战性在教师需要时时面对 新情况、新问题。没有完全相同的两个个体, 是指教育教学对象的多样性, 没有完全相同 的两堂课, 是指教师劳动的复杂与多变性。 教育过程是一个潜移默化、润物细无声的过 程。仅仅凭借在学校所学习的有限时间和课 程, 不足以使教师胜任岗位的需要。教师专 业化成长的内在动力, 来自于教师本身对职 业的认知。终身教育、不断学习, 才能使教 师不断汲取养分, 不断追求卓越。这种终身 的学习行为伴随教师职业生涯的全过程。教 师的终身学习具有一个广义的涵义, 书本知
识、理论学习知识只是其中的一部分。丰富 的教学实践活动是教师专业成长的重要部 分。学习行为体现在教师的每一节课中, 批 改的每一份作业中, 反复推敲、深思熟虑的 每一份教案中。

教师只有加强自身对职业的认知深度和 广度, 专业成长的动力才能像小溪汇入江河 那样, 川流不息、源远流长。持续发展的动 力, 促进教师个体的专业发展; 教师个体不 断完善、提升, 教师群体才能走向专业化。

\section{致谢}

本文为天津市教育科学规划课题 “职业 教育教师专业标准的研究”（VEXII4008） 的部分成果; 天津职业技术师范大学科研基 金 “职业学校教师教育教学能力标准的研究” （SZKT08022）的部分成果。

本项研究得到天津市普通高等学校人文 社会科学重点研究基地: 师范能力与职业能 力研究中心资助。

\section{References}

[1]Dunkin(Australia). Pergamon the latest international teacher encyclopedia, Macmillan press, 1989.

[2]The Outline of National Medium and Long-term Education Reform and Development Plan (2010-2020), Beijing: People's Education Press, 2010.

[3]Ministry of Education of the People's Republic of China, the Theory and Practice of teacher professionalization. Beijing: People's Education Press, 2003. 